\title{
The Rise of Rightwing Populism in Europe and the United States
}

\author{
Winston P. Nagan ${ }^{1}$, Samantha R. Manausa ${ }^{2}$ \\ ${ }^{1}$ Chairperson, Board of Trustees, World Academy of Art \& Science; Sam T. Dell Research Scholar; Professor of Law, \\ Emeritus, United States \\ ${ }^{2}$ Junior Fellow, Institute for Human Rights, Peace and Development, United States \\ Correspondence: Samantha R. Manausa, Junior Fellow, Institute for Human Rights, Peace and Development, United \\ States.
}

Received: August 4, 2018

doi:10.11114/ijsss.v6i10.3650
Accepted: September 15, 2018

Available online: September 25, 2018

URL: https://doi.org/10.11114/ijsss.v6i10.3650

\begin{abstract}
Building off of recent scholarship that has already addressed and debated the myriad causes of the contemporary rise of global populism, the authors seek to explore conceptually the inherent dynamic between identity and mass communications that enables such factors, among others, as economic inequality, systematic corruption by the "elite", or dissatisfaction with neoliberal politics, to motivate populist trends on a global level. The authors seek to strengthen the current understanding of this trend by providing a deeper theoretical explanation for how identity and mass communications have contributed to the international political dynamic that we live in today. The authors will first provide a brief review of relevant recent scholarship on the aforementioned factors seen to be the cause of the current populism trend. They will follow by examining the history of political and group identities in order to identify the ways in which these identities form the building blocks for nationalism and xenophobia, consequences of the rise of rightwing populism. Next, the authors will explain the methods by which people or groups utilize communication to influence others and achieve power. This will include an in-depth discussion of the historical value of narratives and modern communications theories. This will provide a foundational understanding for the final section, in which the authors discuss modern techniques for influencing narratives and effectively communicating to achieve power, including different types of hacking and election-meddling. Ultimately the authors advocate for the strategic utilization of narratives to promote compassion and affection, given the lethality of a future dominated by misinformation and international interference in the democratic process.
\end{abstract}

Keywords: Herrenvolk, Untermensch, non-self others, New Deal State, Neoliberalism, phishing

\section{Introduction}

The current trend of rightwing populism throughout the world is a constant subject of debate by scholars and pundits alike, largely because it implicates other oft-discussed subjects, such as immigration and Islamic extremism. An exploration of the identity-communications dynamic is warranted by the alarming increase of the utilization of false or misleading narratives - now called "fake news"- that has bolstered this global trend. These deceptive narratives have great potential to influence individuals and even mobilize large groups. Through strategic communicational methods such as "fake news", the populist politician appeals to the group identity to gain influence and power. Benjamin Moffitt, in his recent book The Global Rise of Populism: Performance, Political Style, and Representation (2016), asserts that contemporary populist politicians succeed by focusing less on the "message" itself- the ideology of their particular party - and instead focusing on the communication of that message through performance and spectacle. This assertion, along with other relevant scholarship on populist politics, guided the authors toward their primary research question, "How have narratives, as a manifestation of the dynamic between identity and mass communications, contributed to the contemporary global rise of rightwing populism?" The authors were similarly compelled by the incessant flow of op-eds, news stories, and headlines circulating about the subject, especially since the year 2016; the spring Brexit vote in the United Kingdom, followed later in the year by the election of Donald Trump as the President of the United States, brought a renewed sense of urgency to the study of a seemingly contagious trend of rightwing populism. As of March 2018, seventeen nations of the European Union saw populist vote shares in their national elections reach higher than $20 \%$, with Hungary boasting over 65\% (Statista, 2018). For the authors, these staggering statistics demanded an exploration into the ways in which identity formation and communications theory have bolstered the populist trend. 


\section{Relevant Scholarship}

The most recent scholarly discourse on populism centers on the social, political, and economic factors which have contributed to the rise of populism, as well as the interaction of populism and democracy. Mudde and Kaltwasser (2017) identify three fundamental concepts by which populism can be identified: the people, the elite, and the general will. Citing Jean-Jacques Rousseau and Carl Schmitt, they trace early works in classical republicanism to modern understandings of populism through the prioritization of the general will over the will of the individual (Mudde \& Kaltwasser, 2017). Wodak (2015) asserts that the populist movement, beginning roughly two decades ago, has been largely motivated by (and thus identifiable by) nationalist sentiments which have tended to manifest as Anti-Semitism and, now, Islamaphobia. She likewise argues that a process of "normalization of right-wing populist policies" has begun to occur in Europe especially, proclaiming the Austrian populist politician Jörg Haider's rise to power as the beginning of the normalization process (Wodak, 2015). As noted in the Introduction, Moffit (2016) highlights the "performativist" characteristic of the populist leader, viewing the fundamental ideology of the party or movement as less influential than the dramatic spectacles by which populist leaders can communicate that ideology. Such spectacles are frequently used to draw a contrast between "us" and "them"; identification between a leader and his or her audience is essential, and the authors will discuss the process of identification in Section 4 of this article, "Political and National Identity Formation". Most interestingly, Moffit describes the role of crisis in contributing to populist success; he argues that crisis can only truly be understood through performance or spectacle on the part of the leader (Moffit, 2016). Müller (2016) adopts a decidedly anti-populist stances by declaring the trend to be detrimental to democracy, even going so far as to say that democracies which are led by populist leaders are "defective" (Müller, 2016). He sees the movement as being fed by economic inequality, a view shared by a large majority of scholars on the subject; Mudde and Kaltwasser agree, though they identify other factors as well, including systematic corruption by the "elite" and weakness of the state (Mudde \& Kaltwasser, 2017). Judis (2016) likewise agrees but finds that the primary factor in the rise of populism comes from widespread discontent with neoliberal policies. Using the Great Recession of 2008 as a case study, he delineates the effects of neoliberalism on the working class, the "real" people, who were hit hardest by the recession and are now the staunchest supporters of Donald Trump (Judis, 2016). While this is by no means an exhaustive review of recent literature, the authors feel that the aforementioned scholarship is highly compelling and serves as a foundation for the following analysis.

\section{Methodology}

The approach of this paper is influenced by the theory and method of configurative thinking and contextual analysis, pioneered by Harold Lasswell and Myres MacDougal (McWhinney, Lasswell, \& MacDougal, 1993).

\section{Political and National Identity Formation}

All politics inevitably implicates identity in some form. In a broader sense, all culture implicates personal identity. This means that the individual is born into a social unit which begins with the "I", the baby's first cry, which expands to an identity that is influenced by figures including a mother, father, siblings, relatives, clans, tribes, nations, and still larger aggregates. The central problem with the modern emphasis on identity in politics is that the self or "I" is invariably implicated, and it can evolve in various ways so that the "we" is conceptualized as either parochial, xenophobic, tribal, or nationalist. Alternatively, the concept of the self can transcend from localized identification to a larger identification with all of humankind (Nagan, 1993). In this sense, humanity becomes the "we", and it is one with the "I". The pathway to such an inclusive identity remains one of the great challenges of our time.

In general, we tend to see the rise of the modern nation state as encouraging and rewarding forms of loyalty and patriotism to a national sovereign (which can take various forms). The sovereign demands fealty, which holds a powerful influence on identity, and sustains it through the use of symbols of patriotism and loyalty requirements. One finds more inclusivity within the development of the more progressive side of nationalism, in which lesser forms of identification (such as ties to localism, clans, and tribes) are weakened. Nationalism was progressive in that it was able to suggest that political loyalty be founded on citizenship (Nagan, 2001). However, this did not mean that all citizens were equal; power was unevenly distributed, and the poor citizen found his status sustained only marginally. Hence, one of the biggest problems of the nineteenth century, which was readily identified by Marx and Engels, was that citizenship did not extinguish economic or class inequality (Marx \& Engels, 2011). In their view, there was a further step required to ensure class justice: political revolution.

Class, understood as a symbol of identity, could be manipulated by propaganda, philosophical discourse, and the ability to exploit the alienation felt by the lower classes. The evolution of European politics in the nineteenth century tended to reflect issues of class justice and national unity and was also informed by the interests of the sovereign. Nineteenth century Europe never succeeded in having class issues transcend issues of national identity. National identity became a powerful force, and the competition between monarchic sovereigns and other forms of imperial control led to a massive 
world war, which was fed by a powerful nationalistic sense of cultural identity.

\section{National Identity, Non-self Others, and Discrimination}

Two world statesmen recognized the dangerous potential of aggressive national identity: South African Field Marshal J.C. Smuts and American President Woodrow Wilson. Smuts was philosophically gifted and wrote a powerful book called Holism and Evolution, wherein he defines holism as the "fundamental factor operative towards the creation of wholes in the universe" (Smuts, 1927). Although the academic world opted to define holism differently, Smuts utilized his particular definition to argue for the creation of a league of nations. While this book was impressive, it had little effect on the emergence of Afrikaner nationalism in South Africa. Woodrow Wilson saw the war as a misdirected form a nationalism and realized that nationalism itself needed to be tempered. His response to this was a Fourteen Point Program which ambitiously sought to create an international legal institution designed to subordinate the excessive trend of nationalism in the international sphere (Wilson, 1918). Both Wilson and Smuts were keen supporters of the idea of the League of Nations to constrain war fed by restrained nationalism. However, they failed to recognize a technical problem upon which the international system was founded, even before the First World War: the unlimited juridical power of the concept of sovereignty. The League tried to cure this by suggesting that the sovereign could consent to law, so all the League would have to do is acquire the consent of all the sovereigns to create law (and thus constrain sovereign abuses). This was a so-called unanimity rule (Williams, 1925). The Japanese decided to ignore this and pursue their militaristic and imperial ambitions in China; the Italians followed suit by attacking Abyssinia.

Adolf Hitler, perhaps the poster child for ignoring the unanimity rule, politically exploited the idea that the German defeat in World War I was caused by a notorious stab in the back by alleged mercenary Jewish interests. This perspective began to feed the notion of economic grievance in Germany. To many members of the German population, economic grievance was the fault of Western imperialists and their Jewish financiers. During the period between the two world wars, there was constant cultural conflict between the communists and the so-called national socialists. Hitler even sought to co-opt economic alienation into his rightwing ideology and minority victimization by including the word "socialist" in the name of his philosophy.

What emerged in Germany was a strident minority fed by economic and ethnic alienation and racist xenophobia, which proved to be a lethal combination. The notion of ethnic exclusivity was soon fed by the myth of the "master race" (the "Herrenvolk"). Primary candidates for subordination or extermination came to include most of the non-self others ("Untermensch") in the German orbit. These non-self others were designated not only by matters of ethnicity, but of ideology (Fink, Hadler, \& Schramm, 2006). Thus, if a communist fell within the control of the German army, they were destined for quick and effective extermination.

\section{Anti-Semitism in Europe and the United States}

One element of German xenophobia was the lingering endurance of anti-Semitism. Informed by issues of community identification and parochialism, anti-Semitism infected most of Europe and even reached the United States. The endurance and periodic emergence of anti-Semitism is still a matter of debate among social scientists. History can offer some insight: when the Jews were expelled from historical Israel, they settled throughout the diaspora in small communities that almost never fully assimilated into their new political and social environments. The size and minority status of these diasporic communities may have helped instigate and sustain the development of durable traditions in Jewish culture, religion, and religious scholarship. These traditions were necessary elements for Jewish survival, because they contributed to building community identity and social cohesion. However, they also may have perpetuated the dimension of "otherness" felt between the Jews and the majority populations with whom they cohabitated throughout the diaspora (Nagan \& Haddad, 2012). The Jews' advanced capacity to read, write, and count gave them an economic and cultural advantage over the typically uneducated majority populations. Thus, while these skills permitted the Jews to survive, they also identified them as relatively successful non-self others (from the perspective of the majority populations throughout the diaspora).

When the concern of the political economy in Europe changed from status to contract, the Jewish community found a system based on contract to be complementary to their educational and cultural emphases. However, it also proved to bolster the "otherness" and alienation to which the Jews had already been habitually subjected (Nagan \& Haddad, 2012). This could help to explain the endurance of anti-Semitism. It may be noted that the one Christian group that absorbed the educational and commercial traditions of the Jewish community were the Knights Templar, who were stationed for years in Jerusalem. Their economic success led to their eventual extermination by the king of France and the Pope, although their banking tradition survived in Switzerland (The History Channel, 2005).

In the United States, there has always been a long tradition of anti-Semitism, but there were not sufficient Jews to make it a potent and lethal cultural force. Indeed, the tradition of slavery in the South provided a more acceptable application of prejudices. As implied by Abraham Lincoln, the Civil War was motivated by a defense of democracy against 
Southern oligarchy, anchored in racism and muted anti-Semitism. Even with the defeat of the Southern oligarchy, significant aspects of Southern culture continued to reveal racial xenophobia. Perhaps the best example of this is the proliferation and seemingly inexplicable survival of the Ku Klux Klan. Later, this xenophobic impulse solidified in the support of Nazism by rightwing white supremacists. More recently, the impulse has manifested as virulent white nationalism. There are approximately 60 white nationalist organizations propagating racial hatred in the United States in the present day (Southern Poverty Law Center, 2017). Some of these include the National Vanguard, the Aryan Nations, White Lives Matter, and the National Alliance. These groups almost invariably subscribe to the ideology espoused by President Donald Trump and others such as Steve Bannon of Breitbart News.

\section{White Nationalism in Europe and the United States}

The rise of racial nationalism in the United States has been fueled by sentiments of alienation among the lower middle class, particularly by white, working-class Republicans. These citizens may find their position at the lower end of the middle class to be precarious, despite the fact that they were once lifted from dire economic circumstances by the progressive policies of the New Deal. In part, this is because American society has evolved from the social democratic approach of the New Deal to a neoliberal approach, in which wealth and economic opportunity are concentrated in a smaller portion of the middle class and the economic elite are given overwhelming opportunity. In general, this trend has resulted in the middle class suffering economic stagnation, which may explain why the lower middle class fears further deterioration of its position. The upper economic classes conceive of this as largely a matter of finding space in the economy for lower class whites; however, this space is already limited by lower class non-whites and women. Such a conception implies a zero-sum game in which the non-whites and the women receive economic opportunities at the expense of the white lower middle class. The alienation felt by these lower middle-class whites is not directed towards their bosses, but at the labor unions and federal policies which strive for equal economic opportunity. Consequentially, this means that the $40 \%$ who comprise the white lower middle class remain immovable in their support for Trump, and in their antagonism to the social democratic agenda of the post-New Deal Democrats. In this situation, the most obvious candidates for non-self others are immigrants, who are alleged to be criminals, drug traffickers, and more generally a threat to white community and dignity. Not so long ago, the same construction of alleged criminality and violence was used to justify designating African Americans as non-self others. This form of nationalism cannot thrive under progressive economic policies. Thus, the task of white nationalist leaders is to create narratives about white alienation and the non-self others who threaten white community.

A number of European countries have likewise been experiencing the resurgence of rightwing xenophobic nationalism. The rise of ethnic nationalism in Europe is found in at least 16 European countries. The number of people attracted to these far-right parties is not very large, but where the parties lack numbers they compensate with a virulent activist form of political mobilization. Overall, the percentage of votes won by extreme nationalist parties approximates some $25 \%$ of the electorate. It is surprising that Sweden, Denmark, the Netherlands, Austria, and Italy constitute the largest aggregates attracted to the far right. Although Europe is currently enjoying reasonable economic stability, there have emerged two competing theories of where the continent will head. One theory recognizes the distant possibility of a European Union government that would be cosmopolitan and anti-xenophobic. This theory is pitted against one that suggests a subordination of the European Union to an older form of nationalism identification, a narrative that implies alienation from immigrants, Islamic extremism, and perhaps even the European Union. The latter theory has manifested itself as policies in numerous European countries; for example, a famous French right-winger asserted that the state needs to put "native French" citizens first. Similarly, in the Netherlands, the rightwing party wants to ban the Qur'an. In Italy, some leaders openly praise Benito Mussolini. Implicit in all the rightwing propaganda is the idea that traditional nationalism is threatened by non-self others in the form of immigrants.

What ties all of these groups together, both in Europe and the United States, is their goal of reinventing a form of 19th century nationalism which provides for a higher level of cultural affiliation. The older nationalism of Europe was not a cosmopolitan nationalism, and its xenophobic tendencies provided the continent with unparalleled recourse to war and violence. This problem was met at the end of the First World War with the progressivism and cosmopolitan orientation of Woodrow Wilson and J.C. Smuts. The League of Nations, which they established for international peace and security, was a failure because extreme nationalism proved to run unlimited and unrestrained in international combat. The solution to this, in the eyes of Winston Churchill and Franklin D. Roosevelt, was framed in a renewed and enlightened version of Wilsonian progressivism, as reflected in the Atlantic Charter. The Charter identified the following four principles as necessary to transcend destructive nationalistic initiatives: freedom of speech and expression; freedom of conscience and belief; freedom from want; and the freedom from fear (Roosevelt \& Churchill, 1943). These principles essentially provided for the foundations of the United Nations and implicitly required a call for a new orientation to the principles of patriotism and political allegiance. Grounded in the universality of human rights and human dignity, the promise for a postwar world was the promise of a transcendent identity inclusive of all of humanity. The new 
nationalism and its xenophobic objectives are designed to destroy such necessary principles. This represents the great challenge of our time.

\section{Rightwing Political Activism: Signs, Symbols, Narratives, and Communications Theory}

One of the central concerns of modern political identity is the fact that basic communications processes are now deeply influenced by technological capabilities of both state intelligence organizations and variously situated interest groups, both of whom seek to control messaging to select parts of the population. The purpose of this control is to mobilize targeted populations with strengthened inner identifications and antipathy to non-self others. To understand this process, we need to take a closer look at the nature of political communication itself.

All communication involves the interrelationship of communicators and audiences. More precisely, one set of participators in political communication are the initiators of messages, and another set of participators are the recipients of messages, the target audience. In the contemporary era, mass communications involve many full-time specialist initiators focused on the intense distribution of messages to a target audience (Nagan \& Hammer, 2007).

To communicate requires the use of signs and symbols, which are materials or energies whose function is to penetrate the attention span of target audience members. These signs and symbols, when put into the context of contemporary communication systems, radically project messages to millions of recipients with nearly instantaneous speed. Essentially, the communication of signs and symbols is meant to influence the subjectivities of target audience members. Those subjectivities can be influenced to generate responses of compassion or antipathy to non-self others (Lasswell, 1948).

What is left to understand are the specific sequences of signs and symbols which evolve into powerful narratives. Narratives shape the perspectives of people in ways that they do not fully understand, which makes them targets of political manipulation. It is therefore important that we consider the objectives and initiatives of initiators as they communicate their messages. Often initiators may seek to influence subjective expectations and may also seek to control how these narratives manage the target audience. Sometimes initiators may seek to generate political demands to be embraced by the target audience, if not somewhat subconsciously. It is important to keep in mind that there are political consequences to symbols, sings, and the narratives through which they are communicated. The challenge, therefore, is to provide a narrative filled with signs and symbols of compassion and affection, and to limit those signs and symbols which generate negativity and cultural hatred. With the globalization of communications technologies, difficult challenges are posed for authority figures in both the public and private spheres. It is not altogether clear how messages and narratives are to be managed without recourse to censorship and repression. There are numerous strategies of modern communications systems that can alternatively generate socially-beneficent narratives or politically-lethal narratives. It is clear that there is a residual community responsibility to ensure that the manipulation of signs, symbols, and narratives are a conspicuous feature of social solidarity (Nagan \& Root, 2013). The outcomes of communication in our time represent a serious challenge to the integrity of democratic culture, the integrity of individual responsibility, and the importance of responsible choice.

\section{Narratives: Solidarity versus Alienation}

Although the dynamic of power and communication, in which narratives are created and disseminated with the intention of manipulating the populations, proves to be a serious concern of our time, it is not a new concern. The use of narratives to gain power over other people occurs, in some way, every day, and on many levels. Narratives are implicated in nearly every type of social relationship or interaction, whether it be between a parent and child, in friendships and marriages, in social institutions such as schools, churches, and offices, and even in cultural institutions such as the theatre, cinema, and sports centers. Narratives are so fundamental to human communication that the history of society can arguably be seen as the history and sociology of different narratives competing to get the attention of listeners. This may seem somewhat obvious, leading one to question how narratives could have generated so much potential for malicious or manipulative use. This can be answered by the fact that a narrative carries with it different consequences for the people who introject those narratives; after introjection, each person goes on to impact their environment, and all its other members, in some way. Thus, narratives can be tailored to encourage either positive or negative change in a targeted environment; for example, consider the potential effects of a narrative of liberation versus those of a narrative of war.

Given the imperative nature of narratives in establishing power, one wonders what makes some narratives more successful than others. Typically, narratives that promise change and simplicity tend to be more appealing and marketable to populations. The most appealing are narratives that simplify issues and allow people to avoid confronting the complexities of their lives. A large number of people are willing to sacrifice many things - creativity, the joy of learning, free thinking - in order to receive a comforting, pre-cooked truth that promises future wonders. Those who desire power are quick to learn this fact of human nature, and even quicker to craft narratives that allow them to achieve 
power because of it. Donald Trump's 2016 campaign for the American presidency is a prime example of this phenomenon, because it also reveals the sociological value that authoritative figures place in crafting narratives. Trump and his team first identified a minority population that needed a simple and comforting message - uneducated, working-class whites. Recognizing that social groups often identify themselves based on an imperative of fighting something bad or evil (implying that they view themselves as agents of something good), Trump crafted for these whites a narrative of victimization, in which only he could lead them in the fight against the evils which plagued them. He identified these evils as Latin American immigrants, Muslims, and even feminism and globalization. This reinforced group identity among the poor, uneducated whites, and allowed them to unify and target their aggression toward well-defined targets. In turn, there was less potential for in-group fighting among whites, leading them to rally again and again around Trump and his platform.

\section{Rightwing Populism, Technology, Modern Communications Theory, and the Role of Enhanced Intelligence Capabilities}

The electoral systems of Western Europe and the United States have been subject to infiltration and assault by anti-democratic intelligence systems. This assault has been facilitated by a deepening understanding of modern communications theory coupled with technological advances, which have made modern communications technologies accessible worldwide in a very dramatic manner. Our understanding of modern communications theory rests on the work of Claude Shannon and Warren Weaver, who conceptualized communication based on mathematical theorems in what is now known as the S-M-C-R model: a sender generates a communication, which will contain a message; this will be transmitted through a channel of communication to a receiver, who interprets the communication (Shannon \& Weaver, 1999). Within the context of our present generation - the generation of communication - there exist many messages and narratives for the purpose of disrupting democratic systems. Utilizing modern communications theory can allow us to understand the role of enhanced intelligence capabilities within the context of the recent rise of populism.

The sender in this case is representative of the intelligence capacities of selected anti-democratic nation states and suggests the opportunistic appropriation of communications and intelligence technologies by such nation states. The receivers of these messages are target audiences who can be effectively mobilized to support the populist cause. The question of communicating what message reflects a concern with manipulating political messages and narratives to target audiences of states deemed to be opponents. The message typically manifests as efforts designed to undermine the voting integrity of democratic participants, by distorting and misrepresenting political images to cause social division and confusion. The channels through which distorted narratives are communicated in the modern day are plentiful, and recent international events serve as proof. ${ }^{1}$ One such channel is called phishing, in which hacker groups send emails, which are designed to trick the recipient into revealing personal information such as a password, to organizations involved in the voting process of democratic nations, which can potentially allow them to hack voting machines. A recent example of this was by hackers linked to Russia's GRU military agency, who hacked into an organization called VR Systems, which creates hardware and code for voter sign-in machines at polling locations in eight U.S. states (Norden, 2018). Another channel used is simply to bombard a particular website with malware-infested traffic until the site runs too slowly or goes offline. Russia allegedly used this method to sabotage opposition leaders during the 2007 Russian presidential election (Dorell, 2017). A third channel of influencing communication is targeted leaks, wherein a hacker gains access to valuable information, often through phishing, and leaks it at an opportune time during an election season. Another channel, using bot accounts on social media sites to post and spread propaganda, is not technically considered hacking; however, it is an extremely useful tool for influencing communication on a cognitive level. It is obvious that the mastery of these channels of communication, joined with an understanding the sophisticated nature of political propaganda, will continue to be a major threat to the social-democratic systems of Western Europe and the United States, and others.

In part, what is now required is the development of technology for predicting, and blocking, these channels of communication, which are designed to destroy the freedoms we associate with democratic culture and the rule of law. Failure to develop such technologies could result in the devaluation of democratic participation, responsibility, transparency, and accountability; the ultimate culmination of such devaluation will likely be the rise of oligarchy and authoritarian dictatorship.

\section{Conclusion}

In conclusion, the profound challenges posed by the revolution in communications suggests the following: "it is a mistake to trust blindly to the assumption that the presence or absence of shared subjectivity at the end of sequence of 
communication is to be read off in simple fashion from the manifest content of particular words embossed or imprinted," (MacDougal et al, 1994). Narratives have the power to influence the thoughts, behaviors, and environments of individuals; those who can effectively manipulate the "shared subjectivity" that results from a narrative has the ability to influence and mobilize many people, giving that person power. The manipulation of "shared subjectivity" has manifested in this time of technological change in the form of hacking, phishing, creating bot accounts, scamming, and perpetuating propaganda. It emerges as a trend of interference by foreign government intelligence in democratic processes. Russian intelligence dominates the headlines of the news media, with new evidence or consequences revealed seemingly every day. For example, in late July the U.K. Parliament released a report calling for tech companies (with a special nod to Facebook) to be liable for "fake news" on their platforms. This report was motivated by a fear that continual misinformation could threaten international democracy itself. It was seriously prioritized after Facebook went under fire in the United States because of numerous reports by American intelligence agencies that Russians had created fake profiles to spread propaganda on the website, as well as when evidence emerged to suggest that Russian intelligence influenced the 2016 referendum on Britain's exit from the European Union, "Brexit" (The New York Times, 2018). It is clear that Russia intends to acquire as much power in the international sphere as possible through the use of interference technology; given the theory of a cosmopolitan and anti-xenophobic European Union government in the distant future, Russian interference should be a primary concern for defenders of democracy. The technological revolution in global communications has generated significant opportunities for global anti-democratic forces. The consequences of these opportunities would be the corruption of both democracy and its legitimacy, ultimately endangering the values held dear by advocates of global human rights.

\section{Acknowledgements}

Sincere gratitude is extended to the reviewers of the initial draft of this paper.

\section{References}

Dorell, O. (2017, September 07). Alleged Russian political meddling documented in 27 countries since 2004. Retrieved from https://www.usatoday.com/story/news/world/2017/09/07/alleged-russian-political-meddling-documented-27-countr ies-since-2004/619056001/

Euronews. (n.d.). Populist vote share in the national elections of selected European Union (EU) countries as of March 2018*. In Statista - The Statistics Portal. Retrieved September 13, 2018, from https://www.statista.com/statistics/883893/populism-in-europe/

Fink, C., Hadler, F., \& Schramm, T. (2006). 1956: European and global perspectives. Leipzig: Leipziger Universitätsverlag.

Judis, J. B. (2017). The populist explosion: How the great recession transformed American and European politics. Columbia Global Reports.

Lasswell, H. D. (2006). The structure and function of communication in society.

Marx, K., \& Engels, F. (2011). The communist manifesto. New York: Penguin Books.

Marzuni, M. (Writer). (2005, November 7). Decoding the Past: The Templar Code[Television broadcast]. In The History Channel.

Mcwhinney, E., Lasswell, H. D., \& Mcdougal, M. S. (1993). Jurisprudence for a Free Society. Studies in Law, Science and Policy. The American Journal of International Law, 87(2), 335. https://doi.org/10.2307/2203829

Moffit, B. (2017). The Global Rise of Populism: Performance, Political Style, and Representation. S.1.: Stanford University Press.

Mudde, C., \& Kaltwasser, C. R. (2017). Populism: A very short introduction. New York, NY: Oxford University Press. https://doi.org/10.1093/actrade/9780190234874.001.0001

Müller, J. (2017). What is populism? London: Penguin Books.

Nagan, W. P. (October 1993). Ethnic Conflicts, Systems of Identity, and World Order. Remarks at the Workshop for the Society for the Policy Sciences, Yale Law School.

Nagan, W., \& Haddad, A. (2012). Genocide \& the Shoah (The Holocaust): Intellectual Tools for Education \& Public Policy Decision. Canadian Journal of Human Rights.

Nagan, W., \& Haddad, A. (2012). The Holocaust and Mass Atrocity: The Continuing Challenge for Decision. Michigan State International Law Review. 
Nagan, W., \& Hammer, C. (2007). Communications Theory and World Public Order: The Anthropomorphic, Jurisprudential Foundations of International Human Rights. Virginia Journal of International Law.

Nagan, W., \& Root, J. L. (2013). The Emerging Restrictions on Sovereign Immunity: Peremptory Norms of International Law, the U.N. Charter, and the Application of Modern Communications Theory. North Carolina Journal of International Law and Commercial Regulation. Retrieved from http://scholarship.law.ufl.edu/facultypub/589

Nagan, Winston, 'Lawyers Roles, Identity and Professional Responsibility in an Age of Globalism' (2001). Florida Journal of International Law.

Norden, L. (2018, July 16). Mueller's Latest Indictment Suggests Russia's Infiltration of U.S. Election Systems Could Get Worse. Retrieved from

https://slate.com/technology/2018/07/russia-election-hacking-muellers-latest-indictment-suggests-it-could-be-even -more-damaging-next-time.html

Roosevelt, F., \& Churchill, W. (1943). The Atlantic Charter. Washington, D.C: Government Printing Office.

Shannon, C. E., \& Weaver, W. (1999). The mathematical theory of communication. Urbana: University of Illinois Press.

Smuts, J. C. (1927). Holism and Evolution. New York: The Macmillan Company.

White Nationalist Groups. (n.d.). Retrieved from https://www.splcenter.org/fighting-hate/extremist-files/ideology/white-nationalist

Williams, J. F. (1925). The League of Nations and Unanimity. The American Journal of International Law, $19(3), 475$. https://doi.org/10.2307/2188877

Wilson, W. (1918, January 8). Fourteen Point Program. Speech presented at U.S. Congress.

Wodak, R. (2015). The politics of fear: What right-wing populist discourses mean. London: Sage. https://doi.org/10.4135/9781446270073

\section{Copyrights}

Copyright for this article is retained by the author(s), with first publication rights granted to the journal.

This is an open-access article distributed under the terms and conditions of the Creative Commons Attribution license which permits unrestricted use, distribution, and reproduction in any medium, provided the original work is properly cited. 